\title{
Análise Dopplerfluxométrica e angiogênica de tumores mamários caninos
}

\author{
[Dopplerfluxometric and angiogenic analysis of canine mammary tumors] \\ D.M. Navarro ${ }^{1}$, D.M.F. Silva ${ }^{1}$, F.S. Costa ${ }^{2}$, A. Wischral ${ }^{2}$ \\ ${ }^{1}$ Aluno de pós-graduação - Universidade Federal Rural de Pernambuco - Recife, PE \\ ${ }^{2}$ Universidade Federal Rural de Pernambuco - Recife, PE
}

\begin{abstract}
RESUMO
Foi avaliado o comportamento de índices Doppler e a expressão de genes relacionados à neovascularização tumoral, visando caracterizar a vascularização das massas neoplásicas. Foram utilizadas 27 cadelas, com diagnóstico histopatológico de neoplasia mamária, sendo submetidas à avaliação Dopplerfluxométrica tumoral e à coleta de fragmentos neoplásicos para análise de expressão gênica de VEGF, FLT-1, FLK-1 e ATR1. Foram encontrados 22 tumores de origem epitelial (carcinomas) e cinco de origem mesenquimal (sarcomas). Observou-se correlação positiva entre o FLT-1 e as variáveis PS, PI e RI. O FLK-1 apresentou correlação igualmente positiva com os parâmetros PS e PI e uma tendência para RI, enquanto o VEGF retratou correlação positiva apenas com IP. O VEGF também mostrou correlação positiva com seus receptores, porém não apresentou correlação com o ATR1. O FLT1 e o FLK-1 apresentaram ainda correlação positiva entre si e com o ATR1. Houve maior expressão média do VEGF nos tumores epiteliais do que nos mesenquimais. As variáveis PS, PI e RI, associadas com a expressão do VEGF e seus receptores, mostraram-se relevantes para caracterizar a neovascularização de tumores malignos, e a expressão diferenciada do VEGF entre os tipos tumorais pode ser um indicador auxiliar na caracterização de neoplasias mamárias malignas em cadelas.
\end{abstract}

Palavras-chave: cães, neoplasia, Doppler, ATR1, VEGF

\begin{abstract}
The behavior of the tumor Doppler indexes and gene expression related to neovascularization was evaluated aiming to improve the characterization of neoplastic masses vascularization. Twenty-seven bitches with histopathological diagnosis of mammary neoplasia were submitted to tumor Dopplerfluxometric evaluation and collection of neoplastic fragments to analyze the gene expression of VEGF, FLT-1, FLK-1 and ATR1. Were found 22 epithelial (carcinomas) and five mesenchymal (sarcomas) tumors. Positive correlation was observed between FLT-1 and PS, PI and RI. FLK-1 presented a similar positive correlation with the PS and PI parameters, and a tendency for RI $(r=0.45$, $P=0.07)$, whereas VEGF showed a positive correlation just with PI. VEGF also showed a positive correlation with its receptors, but did not present a correlation with ATR1. FLT-1 and FLK-1 also showed positive correlation with each other, and with ATR1. There was higher mean expression of VEGF in epithelial tumors than in mesenchymal ones. The PS, PI and RI associated with the expression of $V E G F$ and its receptors have been shown to be relevant to characterize neovascularization of malignant tumors, and the differentiated expression of VEGF between the types of mammary tumors, may be an auxiliary indicator in the characterization of malignant breast cancers in bitches.
\end{abstract}

Keywords: dogs, neoplasm, dogs, doppler, ATR1, VEGF

\section{INTRODUÇÃO}

Tumor mamário canino é considerado a neoplasia mais comum em cadelas não castradas, atingindo uma taxa média superior a $50 \%$ dos

Recebido em 12 de março de 2017

Aceito em 4 de agosto de 2017

E-mail: deboramnavarro@gmail.com tumores que acometem fêmeas dessa espécie (Feliciano et al., 2012a) e determinando interesse crescente sobre sua avaliação, uma vez que podem servir como modelo animal para estudo em humanos, dada a semelhança dos aspectos tumorais entre as espécies (Cassali et al., 2014). 
Ao longo das últimas décadas, foi estabelecido, por meio de pesquisas, que, como condição essencial para o desenvolvimento tumoral, faz-se necessária a manutenção de um adequado e contínuo suprimento sanguíneo das células neoplásicas. Essa perfusão tecidual exacerbada se deve ao desenvolvimento de microvasos oriundos de células endoteliais pertencentes a capilares circunjacentes às células tumorais, processo este denominado de neovascularização ou angiogênese (Folkman e Klagsbrun, 1987; Pinho, 2005).

A ultrassonografia Doppler é uma ferramenta que permite a obtenção de informações em tempo real, sobre variados aspectos hemodinâmicos dos vasos, como a presença, a direção e o tipo de fluxo sanguíneo (Carvalho et al., 2008). Essa análise envolve a mensuração de diferentes velocidades de fluxo que possibilitam, com base nesses dados, a obtenção de outras informações, como os chamados índices Doppler. Os principais índices utilizados são a relação sístole-diástole (S/D), o índice de resistividade (IR) e o índice de pulsatilidade (IP), tendo eles sido empregados na identificação de alterações vasculares diversas (Carvalho et al., 2008; Feliciano et al., 2012b). A perfusão sanguínea de processos tumorais também tem sido alvo de pesquisas por meio da ultrassonografia Doppler, correlacionando seus resultados a possíveis prognósticos de cada lesão (Nastri et al., 2011).

O padrão de crescimento neoplásico está relacionado ao desenvolvimento de neovascularizações, as quais ocorrem em decorrência de diversos fatores locais estimulantes desse processo (Pinho, 2005). Uma vasta gama de fatores de crescimento já foi identificada como promotores ou inibidores da angiogênese (Ribatti et al., 2002), dentre os quais se pode citar a angiotensina II (ANG II) e o fator de crescimento vascular endotelial (VEGF) como estimuladores da formação de vasos sanguíneos (Feliciano et al., 2012b).

A ANG II é o peptídeo biologicamente ativo do sistema renina-angiotensina, constituindo um regulador importante da homeostase cardiovascular, além de ser reconhecida como um potente mitógeno (Deshayes e Nahmias, 2005). A ANG II também apresenta atuação em variados processos patológicos, sendo descrita como componente participativo da migração e proliferação celular, podendo estar envolvida em formações neoplásicas (Nouet e Nahmias, 2000). Seu receptor ATR1 já foi identificado com incremento de sua expressão em mulheres com carcinoma mamário (Paepe et al., 2001). Outros estudos constataram ainda que esses receptores atuam no aumento dos níveis do fator de crescimento vascular endotelial (VEGF), sugerindo a atuação da ANG II na permeabilidade vascular (Zhang et al., 2004).

O VEGF, também chamado de fator de permeabilidade vascular (VPF), é considerado um potente mitógeno de células endoteliais e tem sido o fator pró-angiogênico mais estudado na oncologia humana (Rebêlo, 2009). Sua ação nas células endoteliais é mediada por dois principais receptores, o FLT-1 e o FLK-1, e o aumento das suas expressões tem sido correlacionado com o aumento do risco de metástase em variados tumores humanos, entre eles as neoformações do tecido mamário (Yoshiji et al., 1996; Pavlakis et al., 2008). Na medicina veterinária, no entanto, apenas estudos mais recentes têm se dedicado na avaliação do VEGF na rotina oncológica dos animais de companhia, havendo escassas informações referentes à relação entre a expressão gênica desse fator e características hemodinâmicas dessas espécies (Feliciano et al., 2012b)

Diante do exposto e visando à associação da ultrassonografia Doppler com a análise da expressão gênica de fatores angiogênicos, objetivou-se neste estudo avaliar o comportamento dos índices Doppler e a expressão dos genes relacionados com a neovascularização, a fim de melhorar a caracterização da vascularização das massas neoplásicas e, assim, possibilitar melhor orientação da conduta terapêutica para cada caso.

\section{MATERIAL E MÉTODOS}

Foram utilizadas 27 cadelas, provenientes do atendimento do Hospital Veterinário, sendo estas encaminhadas com prévia avaliação clínica e laboratorial, sem distinção por idade ou raça, para a seleção do grupo amostral. Para cada cadela avaliada, foi realizada uma ficha de identificação com os dados relacionados ao histórico reprodutivo delas e as principais características tumorais, bem como informações 
relativas à localização anatômica e ao tempo de evolução dos nódulos mamários, além de principais características das massas tumorais. Durante avaliação macroscópica, verificou-se a consistência, as dimensões e o grau de aderência das lesões em tecidos adjacentes, assim como a presença ou ausência de áreas ulcerativas. Nas cadelas que apresentavam mais de uma nodulação nas glândulas mamárias, apenas a maior delas foi utilizada no estudo.

Este projeto foi encaminhado para a Comissão de Ética no Uso de Animais da Universidade Federal Rural de Pernambuco, apresentando licença de número 0095/2015.

Os animais foram submetidos à tricotomia da região abdominal ventral previamente à realização dos exames, sendo todas as avaliações ultrassonográficas realizadas com ultrassom (VetMed - Mindray ${ }^{\circledR}$ ) apresentando transdutor microconvexo multifrequencial (6 a $8 \mathrm{MHz}$ ) e sendo estabelecido o uso da maior frequência para análise das lesões tumorais. Durante a avaliação ultrassonográfica, não foi realizada sedação ou anestesia. A paciente permanecia em decúbito dorsal e/ou lateral, variando-se o posicionamento de acordo com o melhor acesso à glândula mamária comprometida.
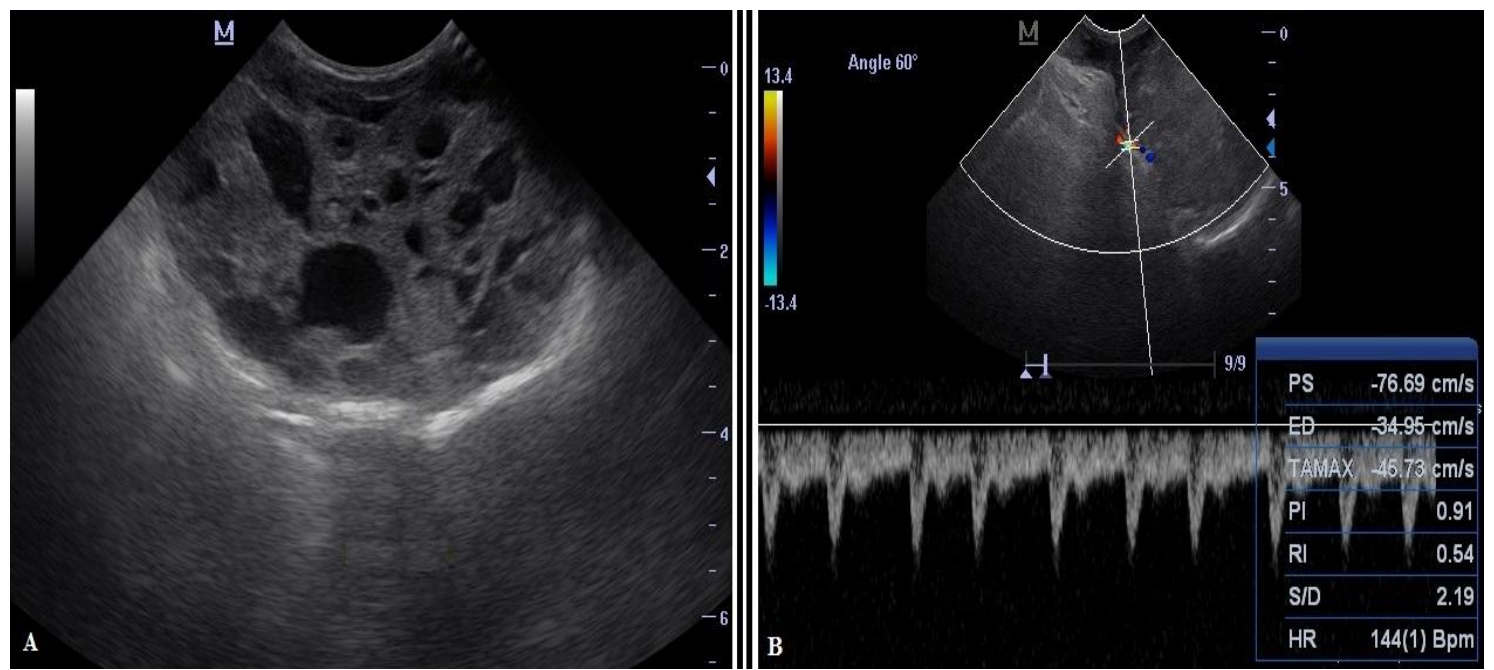

Figura 1. A) Imagem ultrassonográfica de tumor de mama canino de aspecto cavitário, apresentando ecogenicidade mista e ecotextura heterogênea; B) Dopplerfluxometria do nódulo mamário com avaliação dos principais parâmetros hemodinâmicos da lesão.
Foi realizada a análise da massa pelo modo bidimensional para identificação das estruturas vasculares. Uma vez localizados os vasos de maior calibre, foi aplicada a técnica do Doppler colorido, seguida do Doppler pulsado para a avaliação dos fluxos arteriais e venosos presentes na lesão neoplásica. Realizou-se a correção do ângulo de insonação entre o fluxo de Doppler e a direção do segmento vascular para aproximadamente $60^{\circ}$, sendo obtidos e avaliados três ciclos consecutivos de velocidades e amplitudes similares, de cada vaso. A velocidade de pico sistólico (PS), velocidade diastólica final (ED), velocidade média do ciclo (TAMAX), relação sístole / diástole (S/D), assim como os valores do índice de resistividade (RI) (Pourcelot, 1974) e do índice de pulsatilidade (PI) (Gosling et al., 1971) da neovascularização tumoral foram calculados automaticamente pelo software do ultrassom (Fig. 1).

Realizados os exames ultrassonográficos, as cadelas foram submetidas à ressecção cirúrgica da cadeia mamária acometida e às respectivas nodulações, com posterior obtenção das medidas tumorais e coleta do fragmento para análise histopatológica (Fig. 2). 


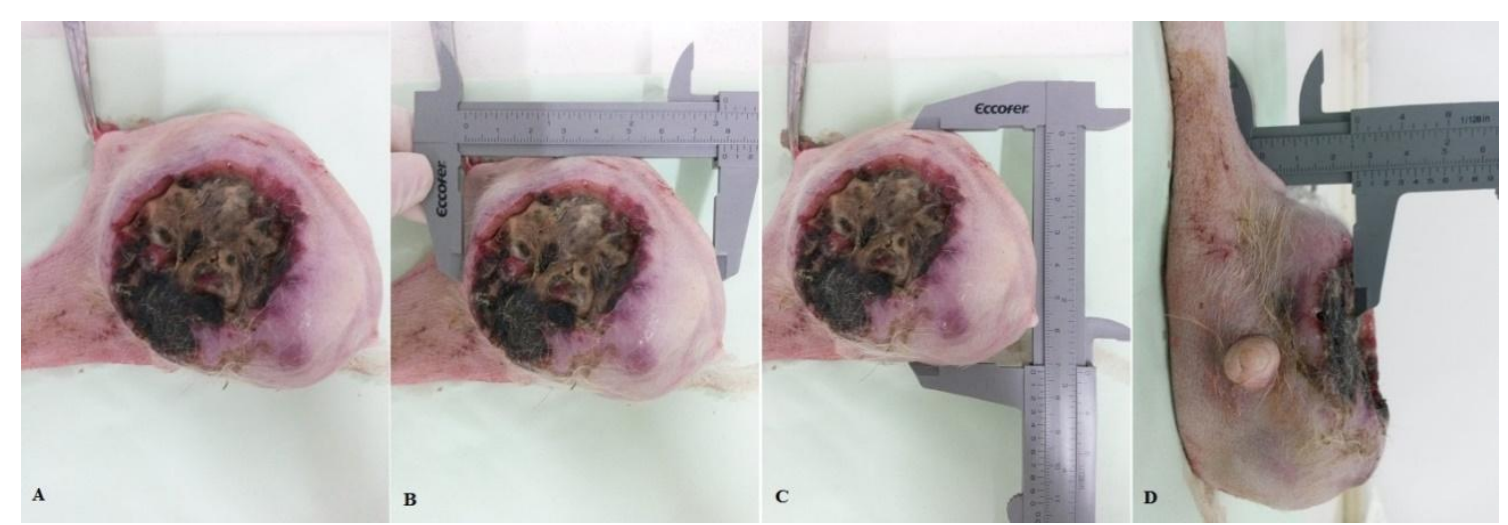

Figura 2. Ressecção cirúrgica de neoformação mamária ulcerada (A). Imagens B, C e D demonstram, respectivamente, a mensuração de largura, comprimento e altura da massa tumoral.

As amostras foram fixadas em formaldeído $10 \%$ (v/v) preparado em PBS 0,01M e pH 7,2. Os fragmentos foram submetidos à clivagem, sendo, em seguida, processados de acordo com as técnicas de rotina para inclusão em blocos de parafina, cortados em micrótomo rotativo 4 micrômetros e corados pela técnica da hematoxilina-eosina (HE), segundo metodologia descrita por Behmer et al. (1976). O diagnóstico histopatológico baseou-se na classificação proposta por Cassali et al. (2014). Nos casos em que não houve a confirmação histopatológica de neoplasia mamária, foi determinada a exclusão do animal do grupo amostral.

Foram coletados aproximadamente 2 a $3 \mathrm{~g}$ de tecido tumoral de cada amostra selecionada, sendo essas amostras acondicionadas em criotubos de $2 \mathrm{~mL}$ acrescidos de TRI ${ }^{\circledR}$ Reagente. As amostras foram transportadas em temperatura de $4^{\circ} \mathrm{C}$ ao laboratório e, em seguida, armazenadas em ultra-freezer $\left(-80^{\circ} \mathrm{C}\right)$ para posterior isolamento do RNA total.

Para o isolamento do RNA total, as amostras de tecido tumoral foram maceradas utilizando-se lâminas de bisturi e pinça, sendo, logo após, realizado o protocolo (Trizol) sugerido pelo fabricante, com modificações.

Para a extração, foram adicionados $500 \mu \mathrm{L}$ de TRI $^{\circledR}$ Reagente por amostra. Essas amostras foram deixadas em repouso por 15 minutos; na sequência, adicionaram-se $100 \mu \mathrm{L}$ de clorofórmio (PA) e, novamente, elas foram colocadas em repouso por mais 15 minutos. As amostras foram centrifugadas na rotação de $12.000 \mathrm{~g}$ por 15 minutos; em seguida, foram retirados $500 \mu \mathrm{L}$ de sobrenadante, o qual foi colocado em um novo tubo coletor de $1,5 \mathrm{~mL}$. Ao sobrenadante coletado adicionou-se a mesma proporção (1:1) de isopropanol (PA), e ele foi deixado 12 horas em freezer $\left(-20^{\circ} \mathrm{C}\right)$ para prosseguir a extração. Após o descanso, as amostras foram centrifugadas na rotação de $12.000 \mathrm{~g}$ por 15 minutos e descartouse calmamente o sobrenadante. Ao tubo foram adicionados $500 \mu \mathrm{L}$ de etanol $70 \%$, para retirar impurezas, o qual foi centrifugado na rotação máxima, por cinco minutos. Após a centrifugação, o sobrenadante foi novamente descartado e o tubo deixado em repouso por 15 minutos, ao qual foi adicionada água Milli-Q para a eluição do RNA total.

Para eliminar a contaminação com DNA genômico, todas as amostras de RNA foram tratadas com RNA-free DNAse (Promega, Madison, USA). O RNA foi quantificado pela absorbância em 260nm, e a pureza do RNA foi determinada com base na relação de 260/280nm por espectrofotometria (NanoVue - PLUS ${ }^{\mathrm{TM}}$ ). Somente amostras com relação entre 1,8 e 2,0 foram utilizadas.

$\mathrm{Na}$ obtenção do DNA complementar total (cDNA), foi utilizado o Kit ImProm-II ${ }^{\mathrm{TM}}$ Reverse Transcription System (Promega ${ }^{\circledR}$ ), sendo adicionado $1 \mu \mathrm{L}$ do oligonucleotídeo iniciador (Oligo(dT)15) e random ao volume de $4 \mu \mathrm{L}$ do RNA total. Todas as amostras foram padronizadas para $1 \mu \mathrm{g}$, em seguida incubadas em termobloco a $70^{\circ} \mathrm{C}$ por cinco minutos e esfriadas a $4^{\circ} \mathrm{C}$ por mais cinco minutos. A essa mistura foram adicionados $4 \mu \mathrm{L}$ do buffer Improm-II ${ }^{\mathrm{TM}}$ (5X), 2,4 $\mu \mathrm{L}$ de $\mathrm{MgCl} 2$ (1,5mM), dNTP $(0,5 \mathrm{mM}$ de cada dNTP) e 1,0 da enzima transcriptase 
reversa Improm-IITM, totalizando um volume final de $20 \mu \mathrm{L}$ da reação, incubada em termobloco $25^{\circ} \mathrm{C}$ por cinco minutos, $42^{\circ} \mathrm{C}$ por 60 minutos e inativação da enzima em $70^{\circ} \mathrm{C}$ por 15 minutos.
A expressão do mRNA para os genes relacionados à neovascularização (VEGF, FLT1, FLK-1, ATR1), avaliada por meio da amplificação de segmentos dos genes com os oligonucleotídeos iniciadores, está relacionada na Tab. 1.

Tabela 1. Sequência dos oligonucleotídeos usados para a amplificação de cada gene em reações de PCR Real-Time

\begin{tabular}{|c|c|c|c|}
\hline Genes & Sequência & Amplificação (bp) & Referência / GeBank \\
\hline VEGF & $\begin{array}{c}\text { F: CAGTGCCTCTCTCTCAAGGC } \\
\text { R: GCTGGCAGGGAACGTCTAAT }\end{array}$ & 127 & XM_540047.5 \\
\hline FLT-1 & $\begin{array}{l}\text { F: AGTAGCACTCTGCTGGCTTC } \\
\text { R: GTGTGAGGTCAGAAAGCCCC }\end{array}$ & 130 & XM_534520.5 \\
\hline FLK-1 & $\begin{array}{l}\text { F: CACGGAGTTGAGCTGTCTGT } \\
\text { R: TCCCAGTTGAAGTCAAGCCC }\end{array}$ & 89 & NM_001048024.1 \\
\hline ATR1 & $\begin{array}{l}\text { F: TTTTAGCCGCATCTCCAGGG } \\
\text { R: AGGCTTTTGGCCAGATCCAA }\end{array}$ & 123 & XM_005634552.2 \\
\hline GAPDH & $\begin{array}{l}\text { F: GTAGTGAAGCAGGCATCGGA } \\
\text { R: GTCGAAGGTGGAAGAGTGGG }\end{array}$ & 108 & NM_001003142.2 \\
\hline
\end{tabular}

Todos os genes foram construídos utilizando-se o programa Pick primer disponível no banco de dados do National Center for Biotechnology Information, Bethesda, MD (NCBI). As sequências apresentaram $100 \%$ de homologia para a espécie canina.

As reações de Real-time PCR foram realizadas com o kit de amplificação MeltDoctor ${ }^{\mathrm{TM}}$ HRMMaster Mix (Applied Biosystems), em termociclador (Rotor-Gene Q da Qiagen ${ }^{\circledR}$ ). As reações foram realizadas em duplicadas com controle negativo para se identificar reações inespecíficas.

Em cada reação, foram utilizados $2,0 \mu \mathrm{L}$ do cDNA (100ng/ $\mu \mathrm{L}), 10 \mu \mathrm{L}$ do HRM-Master Mix, $0,5 \mu \mathrm{L}$ de primer sense e anti-sense $(10 \mathrm{pM})$ e $7,0 \mu \mathrm{L}$ de $\mathrm{H} 2 \mathrm{O}$ Milli-Q, totalizando um volume final de $20 \mu \mathrm{L}$. Os seguintes ciclos foram empregados: temperatura inicial de $95^{\circ} \mathrm{C}$ por 10 min (ativação da enzima), 45 ciclos de $95^{\circ} \mathrm{C}$ por 15 segundos e $60^{\circ} \mathrm{C}$ por 60 segundos (captação da fluorescência). As condições do Melting foram: temperatura de 60 a $95^{\circ} \mathrm{C}$, com incremento de $0,5^{\circ} \mathrm{C} /$ cinco segundos.

O gene de referência utilizado para normatizar as expressões dos genes em estudo foi o GAPDH. A quantificação relativa da expressão dos genes foi calculada pelo método $2-{ }^{\Delta \Delta \mathrm{Ct}}$ (Livak e Schmittgen, 2001).
Os dados que não foram normalmente distribuídos de acordo com o teste de Kolmogorov-Smirnov foram transformados logaritmo natural.

Para avaliação da relação entre os genes e as variáveis Doppler, agrupados por tipo tumoral, foi realizada análise de correlação de Pearson. Para avaliar o comportamento do tipo tumoral em relação às variáveis Doppler e gênicas, utilizou-se análise de variância (ANOVA) com teste de Tukey, a fim de testar as diferenças entre as médias. Foi considerado significativo o valor de $\mathrm{P} \leq 0,05$. Os dados foram apresentados como média \pm desvio-padrão da média.

\section{RESULTADOS}

Entre as 27 amostras avaliadas, foram observadas massas tumorais com tamanho médio de $6,8 \pm 3,2 \mathrm{~cm}$, estando as lesões localizadas em glândula mamária inguinal em $55 \%$ dos casos. Os nódulos, em sua maioria, apresentaram-se superficiais à inspeção e à palpação, o que demonstra ulcerações em apenas $10 \%$ das amostras.

Foram identificados, ao exame histopatológico, 13 tipos diferentes de tumores (Tab. 2). Devido à variabilidade dos tipos tumorais, os tumores foram agrupados, de acordo com sua origem, em 22 de origem epitelial e cinco de origem mesenquimal. 
Tabela 2. Classificação histopatológica dos tumores mamários caninos e suas respectivas frequências e tamanhos

\begin{tabular}{lcc}
\multicolumn{1}{c}{ Tipo tumoral } & Número $(\%)$ & Amostras \\
\hline Carcinoma em tumor misto & $8(29.6)$ & Tamanho* $(\mathrm{cm})$ \\
Carcinoma tubular & $6(22.2)$ & $1,2-10,2^{* *}$ \\
Carcinoma in situ & $2(7.4)$ & $7,3-10,1^{* *}$ \\
Carcinoma sólido & $2(7.4)$ & $2,7-9,0^{* * *}$ \\
Sarcoma em tumor misto & $1(3.7)$ & 6,0 \\
Adenomioepitelioma maligno & $1(3.7)$ & 0,8 \\
Carcinoma anaplásico & $1(3.7)$ & 12,2 \\
Carcinoma mucionoso & $1(3.7)$ & 8,0 \\
Carcinoma papilífero & $1(3.7)$ & 5,0 \\
Carcinoma rico em lipídeos & $1(3.7)$ & 1,0 \\
Fibrossarcoma & $1(3.7)$ & 11,3 \\
Hemangiossarcoma & $1(3.7)$ & 6,2 \\
Lipossarcoma & $1(3.7)$ & 7,9 \\
\hline
\end{tabular}

*Foi considerada a maior dimensão de cada amostra tumoral.

**Menor e maior tamanho de lesão tumoral para o tipo histológico.

No que se refere à avaliação Dopplerfluxométrica, sete lesões neoplásicas não apresentaram vascularização mensurável por meio do exame, em três das quais não foi, ao menos, detectada a presença de fluxo vascular.

Mediante a análise dos dados, foi observada correlação positiva entre o receptor FLT-1 e as variáveis Doppler de velocidade de pico sistólico (PS) $(\mathrm{r}=0,22, \mathrm{P}=0,05)$, índice de pulsatilidade (PI) $\quad(\mathrm{r}=0,93, \quad \mathrm{P}<0,0001) \quad \mathrm{e}$ índice de resistividade $(\mathrm{RI})(\mathrm{r}=0.46, \mathrm{P}=0,05)$. O receptor FLK-1 apresentou correlação igualmente positiva com os parâmetros PS $(\mathrm{r}=0,28, \mathrm{P}=0,03)$ e PI $(\mathrm{r}=$ $0,96, \mathrm{P}<0,0001)$ e uma tendência para RI $(\mathrm{r}=$ $0.45, \mathrm{P}=0.07)$. O VEGF apresentou correlação positiva com PI $(r=0.47, P=0,05)$. Não foram observadas correlações significativas entre os demais genes e as variáveis Dopplerfluxométricas.

Foram observadas correlações significativas entre a expressão dos genes estudados. O VEGF apresentou correlação positiva com seus receptores FLT-1 ( $\mathrm{r}=0,92, \mathrm{P}=0,0001)$ e FLK-1 $(\mathrm{r}=0,34, \mathrm{P}=0,0052)$, porém não apresentou correlação com o receptor da angiotensina (ATR1) $(\mathrm{r}=0,004, \mathrm{P}=0,8656)$. Os receptores de VEGF também apresentaram correlação positiva entre si $(r=0,94, P<0,0001)$ e com o ATR1 (FLT-1: $r=0,49$ / $\mathrm{P}=0,0250$; FLK-1: $\mathrm{r}=0,63$ / $\mathrm{P}=$ 0, 0106).

Quanto ao tipo histológico tumoral, não houve correlação significativa com os parâmetros ultrassonográficos analisados.

Houve diferença significativa entre os tipos tumorais quanto à expressão média do VEGF, sendo maior entre os tumores epiteliais do que nos mesenquimais. No entanto, não foi observada a mesma diferença com as demais expressões gênicas, bem como com as variáveis Doppler. Os dados estão representados na Fig. 3 e na Tab. 3. 

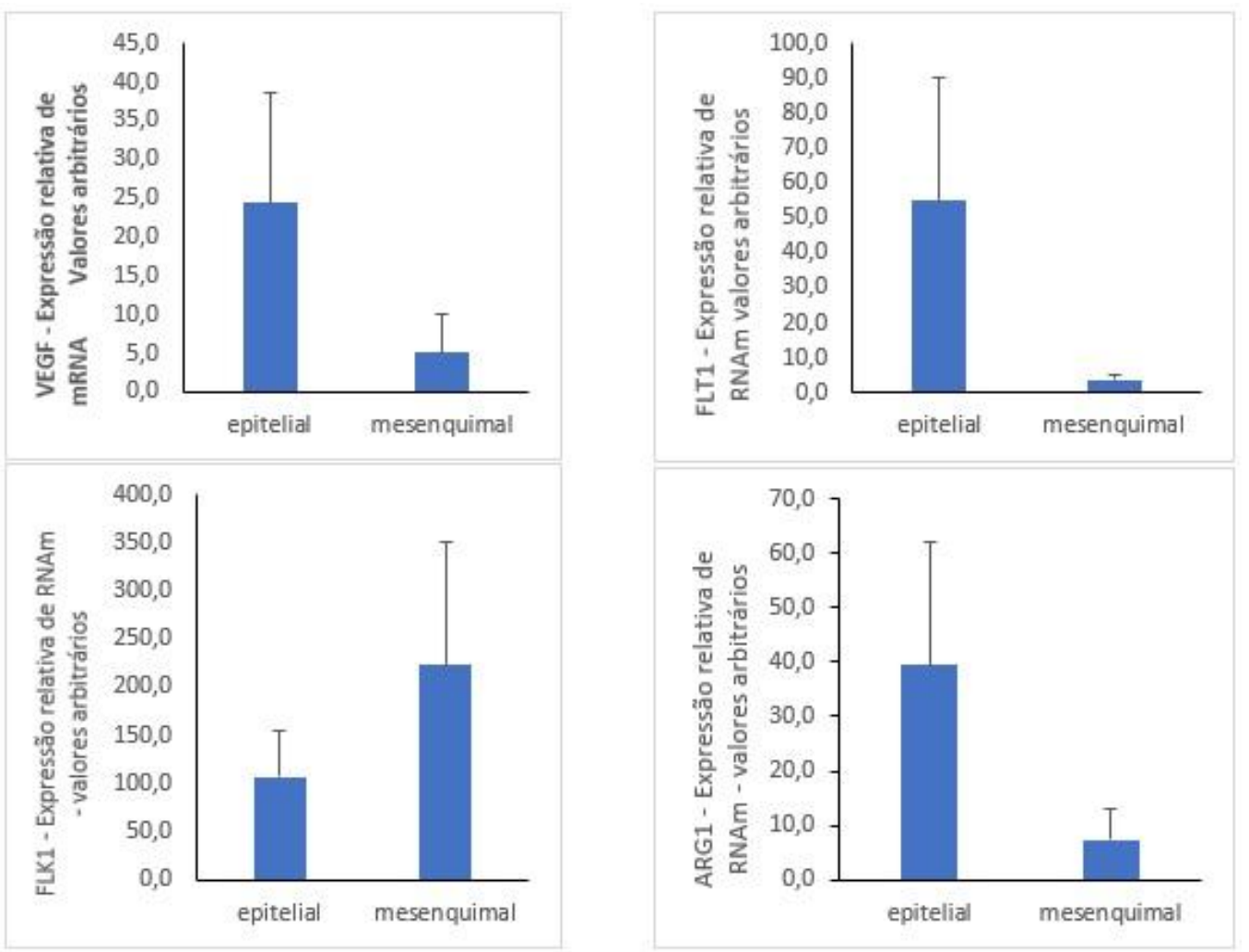

Figura 3. Médias e erro-padrão da expressão dos genes avaliados em tumores mamários de origem epitelial e mesenquimal de cadelas.

Tabela 3. Médias e desvio-padrão dos dados Dopplerfluxométricos de tumores mamários de origem epitelial e mesenquimal em cadelas

\begin{tabular}{ccc} 
Parâmetros Doppler & Tumores epiteliais & Tumores mesenquimais \\
\hline PS & $79,92 \pm 41,76$ & $84,85 \pm 30,00$ \\
ED & $20,88 \pm 12,37$ & $29,90 \pm 4,60$ \\
TAMAX & $35,61 \pm 18,37$ & $48,79 \pm 15,71$ \\
S/D & $5,61 \pm 5,28$ & $2,78 \pm 0,63$ \\
RI & $0,71 \pm 0,14$ & $0,63 \pm 0,09$ \\
PI & $1,97 \pm 2,13$ & $1,08 \pm 0,21$ \\
\hline
\end{tabular}

$\mathrm{PS}=$ pico sistólico; $\mathrm{ED}=$ diastólica final; TAMAX = velocidade média do ciclo; $\mathrm{S} / \mathrm{D}$ = relação sístole/diástole; $\mathrm{RI}=$ índice de resistividade; PI = índice de pulsatilidade.

\section{DISCUSSÃO}

O maior número de neoplasias mamárias de origem epitelial no grupo experimental utilizado neste estudo corrobora a descrição sobre neoplasias mamárias malignas já feita por pesquisas anteriores. O carcinoma mamário é considerado o mais frequentemente observado em cadelas, ao passo que os sarcomas apresentam menor incidência nesta espécie (Misdorp et al., 1999).

A aplicação do estudo Doppler em nódulos mamários baseia-se na detecção de angiogênese tumoral promotora da formação de vasos dentro e em torno da neoplasia (Nastri et al., 2011). Nos tumores analisados, não foi possível a mensuração Dopplerfluxométrica da totalidade 
das amostras, evidência que também ocorreu em outros estudos em pacientes humanos (Chao et al., 1999; Del Cura et al., 2005) e caninos (Feliciano et al., 2012b). Esse fato está possivelmente associado ao pequeno tamanho de algumas massas tumorais que inviabilizaram a correta visibilização das neovascularizações. Como descrito por Nyman et al. (2006), a identificação dos vasos depende dos seus respectivos tamanhos, apesar da relevante sensibilidade da técnica. Além disso, a capacidade de detecção de fluxo por esse método está diretamente relacionada à obtenção do correto ângulo de insonação entre 0 vaso sanguíneo e o feixe sonoro, devendo estar um perpendicular em relação ao outro (Carvalho et al., 2008).

Quanto aos diferentes estudos ultrassonográficos já realizados acerca de tumores mamários caninos, apenas alguns descrevem a análise hemodinâmica das lesões e suas respectivas velocidades e índices Doppler (Nyman et al., 2006; Feliciano et al., 2012b). Na medicina humana, entre as variáveis ultrassonográficas analisadas em estudos oncológicos de fígado e mama, a PS tem se mostrado importante indicador de malignidade das lesões, sendo descrito que picos acima de $20 \mathrm{~cm} / \mathrm{s}$ estão significativamente relacionados a lesões malignas (Dock et al., 1991). O fato de os valores médios de velocidade de PS neste estudo terem sido bem superiores a $20 \mathrm{~cm} / \mathrm{s}$ sugere que esse parâmetro também seja um critério relevante para a caracterização de neoplasias mamárias malignas em cadelas.

A real importância do RI na diferenciação tumoral é controversa na literatura. Alguns autores consideram que a avaliação do RI é relevante para auxílio na diferenciação de neoplasias malignas e benignas, em que massas com altos valores de RI sugerem maior grau de malignidade (Gokalp et al., 2009). Entretanto, outros estudos citam que o desenvolvimento de vasos patológicos em carcinomas, devido à resposta a fatores angiogênicos, pode levar à diminuição da resistência do fluxo sanguíneo intratumoral (Feliciano et al., 2008). Em cadelas, a estimativa do RI parece não ser uma ferramenta útil para a caracterização de tumores mamários malignos. Apesar dos resultados do presente trabalho demonstrarem correlação significativa dessa variável com os fatores de angiogênese tumoral, ela foi classificada como fraca, assim como descrito por Feliciano et al. (2012b), que não conseguiram estabelecer relação entre o RI e o PI com o grau de malignidade das lesões.

Neste estudo, foi observada alta correlação da variável PI com a maioria dos fatores angiogênicos analisados (VEGF, FLT-1 e FLK1), estando esse achado possivelmente relacionado à influência desses genes no aumento da perfusão tumoral. Como descrito por Yonemaru et al. (2006), a expressão do VEGF, simultaneamente à dos seus receptores presentes nas células endoteliais, está associada ao aumento da vascularização, assim como ao desenvolvimento de processos malignos. Em humanos, valores aumentados de PI e RI podem indicar uma tendência de malignidade de tumores mamários, porém este não deve ser considerado o principal critério de malignidade (Del Cura et al., 2005). Estudos em mulheres apontam que, apesar de os valores médios de PI e RI serem comprovadamente superiores nos tumores mamários malignos, quando se analisam os valores médios e os respectivos desviospadrão, existe uma sobreposição dos valores de PI e RI, o que impossibilita o estabelecimento de um ponto de corte entre processos malignos e benignos (Youssefzadeh et al., 1996; Chao et al., 1999).

Um dos primeiros estudos da medicina veterinária sobre VEGF em neoplasias mamárias de cães já descrevia a importância desse fator na promoção da angiogênese e do crescimento tumoral (Graham e Myers, 1999). A positiva correlação encontrada neste estudo entre a variável PS e os receptores do VEGF pode estar relacionada à influência que o FLT-1 e o FLK-1 desempenham no aumento da permeabilidade e dilatação vascular, além do crescimento tumoral e da inibição da apoptose (Restucci et al., 2002). Neste estudo, o valor médio da expressão do VEGF foi maior entre os tumores epiteliais (carcinomas) quando comparado com a média dos tumores mesenquimais (sarcomas). Como descrito por Yoshiji et al. (1996), a expressão gênica do VEGF apresenta valores de destaque nos carcinomas mamários de mulheres quando comparado com outros marcadores tumorais, o que indica que o VEGF pode apresentar um papel crucial na angiogênese de tumores epiteliais. Apesar de existirem limitadas pesquisas analisando o VEGF em tumores 
mamários caninos (Feliciano et al., 2012b), sabese que seu aumento demonstra associação com maior agressividade do tumor e pode ser uma ferramenta auxiliar para estabelecimento do prognóstico de pacientes (Nociti et al., 2015).

Embora já tenha sido descrito que o receptor de angiotensina II, o ATR1, apresenta níveis de expressão aumentados no tumor de mama de mulheres (Paepe et al., 2001), não foi possível demonstrar uma relação significativa da expressão do ATR1 com a do VEGF, bem como com as variáveis Doppler. Tal fato está possivelmente relacionado à obtenção de resultados muito variáveis para esse gene neste estudo, incluindo amostras em que não foi obtida nenhuma expressão dele.

\section{CONCLUSÃO}

Os parâmetros Doppler PS, PI e RI, associados com a expressão do VEGF e seus receptores, mostraram-se relevantes para caracterizar a neovascularização de tumores malignos, independentemente do tipo tumoral. A maior expressão do VEGF em tumores mamários epiteliais do que nos mesenquimais pode ser um indicador auxiliar na caracterização de neoplasias mamárias malignas em cadelas.

\section{REFERÊNCIAS}

BEHMER, O.A.; TOLOSA, E.M.C.; FREITASNETO, A.G. Manual de Técnicas para Histologia Normal e Patológica. São Paulo: Edart, 1976. $256 \mathrm{p}$.

CARVALHO, C.F.; CHAMMAS, M.C.; CERRI, G.G. Princípios físicos do Doppler em ultrasonografia. Cienc. Rural, v.38, p.872-879, 2008.

CASSALI, G.D.; LAVALLE, G.E.; FERREIRA, E. et al. Consensus for the diagnosis, prognosis and treatment of canine mammary tumors - 2013. Braz. J. Vet. Pathol., v.7, p.38-69, 2014.

CHAO, T.; LO, Y.; CHEN, S.; CHEN, M. Color Doppler ultrasound in benign and malignant breast tumors. Breast Cancer Res Treat., v.57, p.193-199, 1999.

Del CURA, J.L.; ELIZAGARAY, E.; ZABALA, R.; LEGÓRBURU, A.; GRANDE, D. The use of unenhanced Doppler sonography in the evaluation of solid breast lesions. Am. J. Roentegenol., v.184, p.1788-1794, 2005.
DESHAYES, F.; NAHMIAS, C. Angiotensin receptors: a new role in cancer? Trends Endocrinol. Met., v.16, p.293-299, 2005.

DOCK, W.; GRABENWOGER, F.; METZ, V. et al. Tumor vascularization: assessment with Duplex sonography. Radiology, v.181, p.241244, 1991.

FELICIANO, M.A.R.; JOÃO, C.F.; CARDILLI, D.J. et al. Neoplasia mamária em cadelas revisão de literatura. Rev. Cient. Elet. Med. Vet., v.9, n.1, 2012a.

FELICIANO, M.A.R.; VICENTE, W.R.R.; SILVA, M.A.M. Conventional and Doppler ultrasound for the differentiation of benign and malignant canine mammary tumours. J. Small Anim. Pract., v.53, p.332-337, 2012 b.

FELICIANO, M.R.A.; VICENTE, W.R.R.; LEITE, C.A.L.; SILVEIRA, T. Abordagem ultrassonográfica da neoplasia mamária em cadela: revisão de literatura. Rev. Bras. Reprod. Anim., v.32, p.197-201, 2008.

FOLKMAN, J.; KLAGSBRUN, M. Angiogenic factors. Science, v.235, p.442-447, 1987.

GOKALP, G.; TOPAL, U.; KIZILKAYA, E. Power Doppler sonography: anything to add to BI-RADS US in solid breast masses? Eur. J. Radiol., v.70, p.77-85, 2009.

GOSLING, R.G.; DUNBAR, G.; KING, D.H. et al. The quantitative analysis of occlusive peripheral arterial disease by a non-intrusive ultrasonic technique. Angiology, v.22, p.52-55, 1971.

GRAHAM, J.C.; MYERS, R.K. The prognostic significance of angiogenesis

in canine mammary tumors. J. Vet. Intern. Med., v.13, p.416-418, 1999.

LIVAK, K.; SCHMITTGEN, T.D. Analysis of relative gene expression data using real-time quantitative PCR and the $2-\Delta \Delta \mathrm{Ct}$ method. Methods, v.25, p.402-408, 2001.

MISDORP, W.; ELSE, R.W.; HELLMÉN, E.; LIPSCOMB, E. Definitions and explanatory notes. Washington: Armed Forces Institute of Pathology, 1999. p.18-27.

NASTRI, C.O.; MARTINS, W.P.; LENHARTE, R.J. Ultrassonografia no rastreamento de câncer de mama. Femina, v.39, p.97-102, 2011. 
NOCITI, R.P.; MACENTE, B.I.; TAVARES, M.R. et al. O papel do fator de crescimento endotelial (VEGF) na formação e progressão de neoplasias mamárias de cadelas. Rev. Bras. Reprod. Anim., v.39, p.341-346, 2015.

NOUET, S.; NAHMIAS, C. Signal transduction from the angiotensin II AT2 receptor. Trends Endocrinol. Metab., v.11, p.1-6, 2000.

NYMAN, H.T.; NIELSEN, O.L.; MCEVOY, F.J. et al. Comparison of B-mode and Doppler ultrasonographic findings with histologic features of benign and malignant mammary tumors in dogs. Am. J. Vet. Res., v.67, p.985-991, 2006.

PAEPE, B.; VERSTRAETEN, V.L.; POETTER, C.R. et al. Growth stimulatory angiotensin II type-1 receptor is upregulated in breast hyperplasia and in situ carcinoma but not in invasive carcinoma. Histochem. Cell Biol., v.116, p.247-254, 2001.

PAVLAKIS, K.; MESSINI, I.; VREKOUSSIS, $\mathrm{T}$. et al. The assessment of angiogenesis and fibroblastic stromagenesis in hyperplastic and pre-invasive breast lesions. BMC Cancer, v.8, p.88, 2008.

PINHO, M.S.L. Angiogênese: o gatilho prolifetivo. Rev. Bras. Coloproct., v.25, p.396$402,2005$.

POURCELOT, L. Applications clinique de léxamen Doppler transcutane. In: PERONNEAU, P. (Ed.). Velocimetrie ultrasonore Doppler. Paris: Semin Inserm, 1974. p.213-240.
REBÊLO, A.M.G. Invasive ductal carcinoma of the breast: relationship between the immunohistochemical expression of endothelial growth factor (VEGF) and BCL-2 oncogene with tumor size and status of the sentinel nodes at the time of histopathological diagnosis of neoplasm. 2009. 74f. Dissertação (Mestrado) - University of Brasília, DF.

RESTUCCI, B.; PAPPARELLA, S.; MAIOLINO, P.; VICO, G. Expression of vascular endothelial growth factor in canine mammary tumors. Vet. Pathol., v.39, p.488-493, 2002.

RIBATTI, D.; VACCA, A.; PRESTA, M. The discovery of angiogenic factors: a historical review. Gen. Pharmacol., v.35, p.227-231, 2002.

YONEMARU, K.; SAKAI, H.; MURAKAMI, M.; YANAI, T.; MASEGI, T. Expression of vascular endothelial growth factor, basic fibroblast growth factor, and their receptor (Flt 1, Flk-1, and Flg-1) in canine vascular tumours. Vet. Pathol., v.43, p.971-980, 2006.

YOSHIJI, H.; GOMEZ, D.E.; SHIBUYA, M.; THORGEIRSSONL, U.P. Expression of vascular endothelial growth factor, its receptor, and other angiogenic factors in human breast cancer. Cancer Res., v.56, p.2013-2016, 1996.

YOUSSEFZADEH, S.; EIBENBERGER, K.; HELBICH, T.; JAKESZ, R.; WOLF, G. Use of resistance index for the diagnosis of breast tumours. Clin. Radiol., v.51, p.418-420, 1996.

ZHANG, X.; LASSILA, M.; COOPER, M.E.; CAO, Z. Retinal expression of vascular endothelial growth factor is mediated by angiotensin type 1 and type 2 receptors. Hypertension, v.43, p.276-281, 2004. 